\title{
Strategies for Colorectal Cancer Screening
}

\author{
Uri Ladabaum, ${ }^{1}$ Jason A. Dominitz, ${ }^{2}$ Charles Kahi, ${ }^{3}$ Robert E. Schoen ${ }^{4}$
}

${ }^{1}$ Division of Gastroenterology and Hepatology, Department of Medicine, Stanford University School of Medicine, Stanford, CA; ${ }^{2}$ Gastroenterology Section, VA Puget Sound Health Care System, Seattle, Washington, Division of Gastroenterology, Department of Medicine, University of Washington School of Medicine, Seattle, Washington; ${ }^{3}$ Indiana University School of Medicine and Richard L. Roudebush VA Medical Center, Indianapolis, IN ; ${ }^{4}$ Division of Gastroenterology, Hepatology and Nutrition, University of Pittsburgh, Pittsburgh, PA

Word count: Tables: $4 \quad$ Figures: 1

Contact information:

Uri Ladabaum, M.D., M.S.

Division of Gastroenterology and Hepatology

Stanford University School of Medicine

430 Broadway Street

Pavilion C, 3rd Floor C-326

Redwood City, CA 94063-6341

650-725-5135; Fax 650-724-0533

e-mail: uri.ladabaum@stanford.edu

Jason A. Dominitz, MD, MHS

VA Puget Sound Healthcare System

1660 S. Columbian Way (111-S-Gastro)

Seattle, WA 98108

Jason.Dominitz@va.gov

206-277-3558

Charles J. Kahi, MD, MS, AGAF

Indiana University School of Medicine

Richard L. Roudebush VA Medical Center

$1481 \mathrm{~W} 10$ th street, $111 \mathrm{G}$

Indianapolis, IN 46202

Phone: (317) 988-3682

Fax: (317) 988-5313

E-mail: ckahi2@iu.edu

Robert E. Schoen, MD MPH

Mezzanine Level, C Wing, PUH

200 Lothrop St.

Pittsburgh, PA 15213-2582

This is the author's manuscript of the article published in final edited form as: 
Disclosure: UL, advisory board (UniversalDx, Lean Medical), consultant (Covidien, Motus GI, Quorum, Clinical Genomics); JAD, none; CK, none; RS, none

Acknowledgements: This material is the result of work supported in part by resources from the Veterans Health Administration. The views expressed in this article are those of the authors and do not necessarily represent the views of the Department of Veterans Affairs. 


\section{Abstract}

The incidence of colorectal cancer (CRC) is increasing worldwide. CRC has high mortality when detected at advanced stages, yet it is also highly preventable. Given the difficulties in implementing major lifestyle changes or widespread primary prevention strategies to decrease CRC risk, screening is the most powerful public health tool to reduce mortality. Screening methods are effective but have limitations. Furthermore, many screen-eligible persons remain unscreened. We discuss established and emerging screening methods, and potential strategies to address current limitations in CRC screening. A quantum step in CRC prevention might come with the development of new screening strategies, but great gains can be made by deploying the available CRC screening modalities in ways that optimize outcomes while making judicious use of resources.

Keywords: colonoscopy; fecal immunochemical test; fecal occult blood test; sigmoidoscopy 
Screening can greatly reduce colorectal cancer (CRC) incidence and mortality. So, have we solved the CRC problem? The increasing incidence of CRC worldwide and in younger persons indicates that many challenges remain. Screening has not eliminated CRC. Primary prevention is difficult, so CRC control efforts rely largely on screening. Approximately one-third of screen-eligible Americans have not been screened; ${ }^{1}$ an estimated $46 \%-63 \%$ of deaths from CRC in the United States (US) have been attributed to missed screening opportunities. ${ }^{2}$ Therefore, the effectiveness of a screening strategy depends not only on screening test performance characteristics, but also on patient adherence. The burden of CRC might be further reduced with successful deployment of the screening strategies we already have, which we know work, as well as innovations in screening methods or risk stratification and personalized screening.

\section{Screening Strategies}

Although CRC is the second leading cause of cancer death in the US, CRC incidence and mortality have been decreasing substantially over the past several decades. ${ }^{3}$ It is estimated that much of this reduction can be attributed to screening ${ }^{4}$ with removal of precancerous polyps and detection of early stage CRC. ${ }^{5}$

$\mathrm{CRC}$ is the only cancer for which screening has been proven to reduce cancer mortality in average-risk women and average-risk men. Several screening tests are available, each with strengths and limitations. The quality of evidence to support these screening tests varies. Randomized controlled trials have found significant reductions in CRC mortality among patients screened by guaiac-based fecal occult blood tests (gFOBTs) or flexible sigmoidoscopy, whereas observational studies support the effects of fecal immunochemical tests (FITs) and screening colonoscopies in reducing deaths. Data are available from only cross-sectional studies of the 
effects of multi-target stool DNA (mt-sDNA) test and computed tomography colonography (CTC), comparing performance characteristics with those of colonoscopy. There have been no head to head studies to demonstrate that any one test is superior to another for reducing CRC mortality or incidence.

\section{Stool-based tests}

The gFOBT uses the pseudoperoxidase activity of heme to detect the presence of blood in stool. Dietary modification and avoidance of non-steroidal anti-inflammatory drugs and vitamin $\mathrm{C}$ are recommended to avoid false-positive and false-negative results, respectively. ${ }^{6}$ Test takers are asked to collect 3 stool samples for each screening round. Data from 5 randomized controlled trials, comprising more than 440,000 participants with 11-30 years of follow up, support the efficacy of this test.

Screening with gFOBTs every 2 years (biennially) reduced CRC mortality by $9 \%-22 \%$ over 2-9 rounds of screening (Table 1). ${ }^{7-12}$ In a study that directly compared annual or biennial gFOBTs to usual care in the US, annual screening resulted in a greater reduction in CRC mortality than biennial screening over 30 years $(32 \%$ vs $22 \%) .{ }^{9} \mathrm{CRC}$ incidence was reduced by $20 \%$ with annual screening vs $17 \%$ with biennial screening over 18 years of follow-up. ${ }^{13}$ There were greater reductions in CRC-specific mortality among men than women in some studies. ${ }^{9}$ The gFOBT used in these studies (Hemoccult II) detects CRC with lower levels of sensitivity than available gFOBTs (which detect CRC with 62\%-79\% sensitivity and of 87\%-96\% specificity) (Table 2). ${ }^{14,15}$

The FIT has largely replaced gFOBT due to the relative advantages of the FIT, which uses an antibody to detect human globin and is therefore not affected by diet. Only 1 stool 
sample is required for many available FITs, and studies have demonstrated significantly greater adherence to FIT than the gFOBT. ${ }^{16}$ There have been no randomized controlled studies of the effectiveness of FIT in reducing CRC mortality or incidence. However, a study that examined staggered initiation of biennial FIT screening across regions in Italy found a $22 \%$ reduction in CRC mortality in regions that offered FIT early compared with regions that delayed FIT screening (Table 1). ${ }^{17}$ Observational cohort studies reported a $10 \%$ reduction in CRC incidence ${ }^{18}$ and a $62 \%$ reduction in CRC mortality attributable to FIT. ${ }^{19}$ A meta-analysis of test characteristic studies reported that FIT detected CRC with a pooled sensitivity of 79\% and specificity of $94 \%$ (Table 2). ${ }^{20}$ These studies are based on 1-time application compared with colonoscopy and do not account for potential detection of neoplasia on future rounds of screening. Based upon superior test characteristics, lack of need for dietary or medication modification, and greater adherence, annual FIT is recommended over gFOBT. ${ }^{21}$

$\mathrm{CRC}$ is associated with genetic and epigenetic changes. ${ }^{22} \mathrm{CRC}$ cells are shed into the stool, and their DNA alterations can be detected. However, the CRC cell DNA must be distinguished from bacterial DNA, which is much more abundant. The mt-sDNA test combines a FIT with assays for abnormally methylated regions of DNA associated with colorectal carcinogenesis. ${ }^{23}$ Subjects taking the test are not required to have any dietary or medication modifications, though test completion requires mailing of a test kit to the subject, who must then return a FIT and stool sample in buffer. Navigators, supplied by the manufacturer, help improve adherence.

There have been no randomized controlled studies of the effects of mt-sDNA test on CRC mortality and incidence. A study compared results of 1-time use of mt-sDNA vs FIT in 9989 average-risk adults who underwent colonoscopy as the reference standard. The mt-sDNA 
test detected CRC and advanced adenoma with $92.3 \%$ sensitivity, vs $73.8 \%$ sensitivity for the FIT, but with only $86.6 \%$ specificity, compared with $94.9 \%$ for the FIT (Table 2 ). ${ }^{23}$ The mtsDNA test detected sessile serrated polyps $\geq 10 \mathrm{~mm}$ with $42.4 \%$ sensitivity compared with $5.1 \%$ sensitivity for the FIT. There are limited data on the appropriate surveillance interval, though the manufacturer recommends screening every 3 years. It is not clear how to manage patients with abnormal results from the mt-sDNA test but normal results from colonoscopy.

\section{Direct visualization}

Flexible sigmoidoscopy provides direct visualization of the distal portion of the colorectum and the opportunity to biopsy and/or remove polyps. Bowel preparation consists of enemas with or without oral magnesium citrate, and no sedation is required. Four long-term (11-17 years) randomized controlled trials compared effects of flexible sigmoidoscopy with no screening. ${ }^{24-27}$ A meta-analysis $(n=458,002)$ found that flexible sigmoidoscopy decreased CRC morality by $27 \%$ (95\% CI, $18 \%-34 \%$ ), compared to no screening at 11-12 years of follow up, in intention to screen analyses (Table 1). ${ }^{12}$ Moreover, CRC incidence was reduced by $21 \%$ ( $95 \%$ CI, $15 \%-$ $25 \%$ ) with flexible sigmoidoscopy compared with no screening. In per-protocol analyses, flexible sigmoidoscopy resulted in 38\%-43\% reductions in CRC mortality and 31\%-33\% reductions in CRC incidence. ${ }^{27,28}$

The reduction in CRC mortality and incidence was significant for only distal CRC, with an incidence rate ratio of 0.63 (95\% CI, 0.49-0.84) compared with 0.90 ( $95 \% \mathrm{CI}, 0.77-1.04$ ) for

proximal CRC. ${ }^{12}$ This mortality reduction benefit appears to be greater for men than women, ${ }^{29}$ possibly due to differences in neoplasia distribution. Flexible sigmoidoscopy is recommended every 5 years. 
Colonoscopy, which is indicated after other less-invasive tests are positive, can also be used for primary screening. Colonoscopy requires dietary modification and administration of a purgative preparation. Most individuals undergo colonoscopy with sedation, requiring the assistance of someone to transport them after the procedure. No randomized trials have been completed that evaluated the efficacy of colonoscopy, but the NordICC study, a randomized trial that is underway in Northern Europe, is comparing colonoscopy to no organized screening. ${ }^{30,31}$ Cohort and case-control studies found an association between lower endoscopy and reduced CRC mortality and incidence (Table 1). ${ }^{32-42}$ A large prospective cohort study of nearly 89,000 nurses and other health care professionals found that, over 24 years of follow up, colonoscopy was associated with a $68 \%$ reduction $(95 \% \mathrm{CI}, 55 \%-76 \%)$ in CRC-specific mortality compared with no exposure to colonoscopy. ${ }^{37}$ Individuals who underwent colonoscopy with polypectomy were found to have a $43 \%$ reduction in CRC incidence compared to those with no lower endoscopy.

Although CRC screening tests are often compared to colonoscopy, colonoscopy can miss lesions as well. In studies comparing colonoscopy to CTC, or to colonoscopy enhanced by knowledge of CTC results, the estimated per-person sensitivities ranged from $89.1 \%$ to $94.7 \%$ for adenomas $\geq 10 \mathrm{~mm}$ and from $74.6 \%$ to $92.8 \%$ for adenomas $\geq 6 \mathrm{~mm}$ (Table 2 ). ${ }^{12}$ A systematic review of tandem colonoscopy studies reported miss rates of $26 \%$ for adenomas (95\% CI, $23 \%-$ $30 \%), 9 \%$ for advanced adenomas (95\% CI, 4\%-16\%), and $27 \%$ for serrated polyps ( $95 \% \mathrm{CI}$, $16 \%-40 \%) .{ }^{43}$ Screening colonoscopy is recommended every 10 years.

CTC also allows for visualization of the entire colorectum. CTC is typically performed after administration of a bowel preparation and/or an agent to radiographically tag stool for digital subtraction. $\mathrm{CO}_{2}$ insufflation is achieved via a rectal balloon catheter. There are no studies 
evaluating the effect of CTC on CRC incidence or mortality. In a meta-analysis that compared the effects of CTC with those of colonoscopy, the per-person sensitivity of CTC for adenomas $\geq 10 \mathrm{~mm}$ ranged from $66.7 \%$ to $93.5 \%$, with specificity values ranging from $96.0 \%$ to $97.9 \%$ (Table 2). ${ }^{12}$ For adenomas $\geq 6 \mathrm{~mm}$, sensitivity ranged from $72.7 \%$ to $98.0 \%$, with specificity values ranging from $79.6 \%$ to $93.1 \%$. In a randomized controlled trial that compared CTC with colonoscopy for population screening, detection of high-risk sessile serrated lesions (dysplastic and/or $\geq 10 \mathrm{~mm})$ was significantly lower with CTC $(0.8 \%)$ than with colonoscopy $(4.3 \%) .{ }^{44} \mathrm{CTC}$ is mostly used after incomplete colonoscopy and for individuals at high risk for colonoscopy, but some centers use it for primary screening. The risk of radiation associated with contemporary CTC protocols is probably minimal, but the balance of benefit vs harm of detecting extracolonic findings remains uncertain. CTC is recommended every 5 years.

The US Food and Drug Administration (FDA) approved a blood-based test that detects circulating methylated DNA encoding septin 9, a plasma marker of CRC. This test is only approved for individuals who have been offered and declined the screening tests recommended by the US Preventive Services Task Force (USPSTF). ${ }^{45}$ In a large prospective study, this test detected CRC with $48.2 \%$ sensitivity and $91.5 \%$ specificity. ${ }^{46}$ When archived samples were retested with a next-generation assay, it identified early-stage CRC with 59\% sensitivity and later-stage CRC with $87 \%$ sensitivity, and specificity values of $79 \% .{ }^{47}$ A meta-analysis of studies of this assay found a pooled sensitivity of $67 \%$ and specificity of $89 \%$ for detection of CRC. ${ }^{48}$

Capsule colonoscopy involves ingestion of a large pill-sized camera that records images during its transit through the intestine. Highly effective bowel preparation is required, typically involving use of booster doses and/or a prokinetic agent. This procedure is not recommended for screening by the USPSTF, or approved by the FDA as a first-line screening test, though it is 
approved for patients with incomplete colonoscopy despite adequate bowel preparation. Studies of capsule colonoscopy are limited to test-characteristic studies compared to colonoscopy. In a study of 695 individuals who underwent capsule colonoscopy followed by standard colonoscopy, the per-person sensitivity for cancer was $100 \%$ (in 4 patients), while the per-person sensitivities were $92 \%$ and $88 \%$ for adenomas $\geq 10 \mathrm{~mm}$ and $\geq 6 \mathrm{~mm}$ adenomas, respectively, with specificity of $95 \%$ and $82 \%$ for $\geq 10 \mathrm{~mm}$ and $\geq 6 \mathrm{~mm}$ adenomas, respectively. ${ }^{49}$ As with CTC, sessile serrated polyps were difficult to detect, accounting for $26 \%$ of false-negative results in patients with polyps $\geq 6 \mathrm{~mm}$.

\section{Effectiveness studies vs test-characteristic studies}

Comparisons of colonoscopy's benefits in cohort studies to the intent to screen results of gFOBT or flexible sigmoidoscopy in randomized trials are compromised by selection bias. Individuals who undergo colonoscopy have, by definition, perfect screening adherence. Studies that compare one-time application of screening tests to colonoscopy (mt-sDNA and FIT) do not reflect the real-world implementation of these tests. For example, no data are available on the programmatic application of annual FIT compared with every 3-year screening with the mt-sDNA test. Modeling studies have attempted to address these questions, but are limited by the absence of actual implementation data.

\section{Programmatic Issues}

The effectiveness of screening depends not only on the screening test characteristics, but also on patient adherence. Worldwide, organized CRC screening programs are proliferating. Although most CRC screening in the US is opportunistic, there are a few examples of organized screening 
(such as Kaiser Permanente and the Veterans Health Administration). In opportunistic screening, tests that are performed infrequently (such as colonoscopy), and therefore require fewer reminders, gain appeal. In organized screening, tools to identify screen-eligible individuals (such as clinical reminders in the electronic health record) and to promote adherence, such as navigators, are required. Through the use of direct to patient annual FIT outreach, with colonoscopy as a secondary option, Kaiser Permanente of Northern California increased the proportion of individuals up to date with screening from $38.9 \%$ to $82.7 \%$ over 15 years. ${ }^{50}$ This was associated with a $25.5 \%$ reduction in annual CRC incidence and a 52.4\% reduction in CRC mortality as well as an increase in the rate of colonoscopy after a positive FIT from $41.1 \%$ to $83.1 \%$.

Test specificity has important implications for programmatic screening. Tests with lower specificity will result in a larger number of false positives, leading to additional diagnostic evaluations with their risks and costs. It remains to be seen how providers and patients will deal with normal colonoscopies after abnormal non-invasive screening, as some have advocated repeat screening earlier than would otherwise be recommended. ${ }^{51,52}$

\section{Comparative Effectiveness}

We must use caution in comparing results of studies of different screening modalities because of differences among study populations and in the adherence rates achieved with specific implementation strategies. No long-term comparisons between screening alternatives have been completed, but 4 large randomized controlled trials are underway. ${ }^{30,53-55}$ The Veteran Administration's CONFIRM trial and the Spanish COLONPREV trial are comparing one-time colonoscopy vs annual or biennial FIT, respectively, and the Swedish SCREESCO trial is comparing 
one-time colonoscopy vs 2 rounds of FIT vs a no intervention control. The NordICC trial is comparing colonoscopy vs no organized screening.

No trial will ever be conducted to compare all screening options against each other. Even if such a trial were ever launched, how would we evaluate a new, promising test? A consensus has emerged that, building on the effectiveness of screening demonstrated in randomized trials of gFOBT and sigmoidoscopy, it is reasonable to compare CRC screening tests to each other based on their test performance characteristics, including sensitivity for early-stage CRC and advanced precancerous lesions, and specificity. ${ }^{56}$

Available comparative data include results from the first rounds of testing in randomized trials, with lesion detection as a surrogate marker. Computerized models have been developed to make long-term projections of clinical outcomes (CRC cases and deaths prevented, and life-years gained).

\section{Single-round vs programmatic screening and the importance of participation}

In the first-round of the COLONPREV study, participation rates in the FIT and colonoscopy groups were $34.2 \%$ and $24.6 \%$, respectively. ${ }^{54}$ In those actually screened, detection rates for FIT vs colonoscopy were $0.3 \%$ vs $0.5 \%$ for CRC and $2.4 \%$ vs $9.7 \%$ for advanced adenoma. However, in the intent to screen analysis, which accounts for the differential participation, detection rates for FIT vs colonoscopy were $0.1 \%$ vs $0.1 \%$ (not significant) for CRC and $0.9 \%$ vs $1.9 \%$ (significant) for advanced adenoma. It is anticipated that the programmatic effectiveness of the FIT intervention will improve over subsequent cycles, as FIT is offered again every 2 years and more CRCs and advanced adenomas are detected. 
In a randomized trial of CTC vs colonoscopy in The Netherlands, participation rates in the CTC and colonoscopy groups were $34 \%$ and $22 \%$, respectively. ${ }^{57}$ In those actually screened, detection rates for CTC vs colonoscopy were $0.5 \%$ vs $0.5 \%$ (not significant) for CRC and $5.6 \%$ vs $8.2 \%$ (significant) for advanced adenoma.

Longitudinal participation patterns through multiple cycles of fecal testing have been described. ${ }^{58,59}$ These include consistent screeners; intermittent screeners with late entry, drop out, or intermittent participation; and consistent non-responders. The participation patterns attained in the ongoing prospective trials will have implications for the interpretation of the trials' results. FIT is being offered yearly in CONFIRM and every 2 years in COLONPREV over 10 years, and 2 years apart for only 2 rounds in SCREESCO; furthermore, the FIT arms include programmatic invitations every cycle, while colonoscopy is being offered only once, although in CONFIRM, the follow up of those who fail to complete their colonoscopy is left to local policy, allowing for heterogeneity in subsequent efforts to enhance adherence. ${ }^{53}$ In opportunistic screening, it is common for patients to present for colonoscopy after several unsuccessful recommendations by primary care providers to screen, sometimes over years. Repeated invitations might yield higher cumulative participation rates than once-only invitations. Interpretations of the intention-to-screen results in the ongoing trials will need to consider whether the participation patterns observed, which reflect the specific study populations and invitation protocols, can be generalized to other settings.

\section{Estimating long-term comparative effectiveness with modeling}

Multiple CRC screening models have been developed worldwide to address questions that are unlikely to be answered directly by clinical trials. In the US, 3 models from the National Cancer Institute's Cancer Intervention and Surveillance Modeling Network (CISNET) consortium have 
informed the USPSTF ${ }^{60,61}$ and American Cancer Society (ACS) screening guidelines. ${ }^{62-64}$

Table 3 shows the long-term effects of screening on CRC incidence and mortality that is projected for 5 screening modalities, with optimal participation over time, by the 3 CISNET models ${ }^{61,65}$ and a fourth model that has been validated against prospective trials of gFOBT and sigmoidoscopy. ${ }^{66,67}$ The estimated CRC incidence reductions with annual FIT and colonoscopy, for instance, range from $47 \%$ to $72 \%$ and from $62 \%$ to $88 \%$, respectively; the estimated CRC mortality reductions with annual FIT and colonoscopy range from $72 \%$ to $81 \%$ and from $77 \%$ to $90 \%$, respectively. In general, models tend to predict that, among those participating consistently in screening, colonoscopy every 10 years yields the largest reductions in CRC incidence and mortality, but the programmatic effects of other modalities approaches that of colonoscopy (see Table 3). As expected, and desired, models' predictions of comparative effectiveness are greatly affected if differential participation patterns are assumed between strategies.

\section{Cost Effectiveness}

Three systematic reviews (published in 2000, 2010, and 2016), covering 1993-2016, ${ }^{68-70}$ assessed the multiple cost-effectiveness analyses of CRC screening that have been performed worldwide, including regional epidemiology data and costs (Table 4). These analyses tend to focus on highincome countries, reflecting the availability of resources and the relative burden of disease and public health priorities vs low-income countries. ${ }^{71,72}$

The apparently small average gains in discounted life-years per person predicted by the models (Table 4) reflect relatively large gains in undiscounted life-years by the small percentage of people who benefit by avoiding CRC-associated death, divided by the entire population. ${ }^{73}$ Is it 
reasonable for models to predict that CRC screening prolongs life? An insightful meta-analysis of screening sigmoidoscopy randomized trials reported a relative risk of all-cause mortality of 0.975 for screening vs control. ${ }^{74}$ It is therefore reasonable for modeling studies to project reductions in overall mortality even if individual trials are not powered to detect it.

There are four principal conclusions. Compared with no screening, all screening modalities are generally predicted to be cost effective (see Table 4) ${ }^{68-70}$ As the costs of treatments for advanced CRC have increased, with proportionately modest gains in survival, the cost effectiveness of CRC screening has improved, with many strategies becoming cost-saving in the US. ${ }^{68-70,75,76}$ When participation levels are the same among strategies, there is no uniformly favored strategy. ${ }^{68-70}$ Established strategies are generally favored over emerging strategies such as CTC and mt-sDNA tests. $^{69,70}$

In a analysis of the effects of participation rates and program costs, opportunistic FIT was cost saving. ${ }^{67}$ An organized FIT program with higher participation rates was substantially more effective and was highly cost effective, but was no longer cost saving, due to the additional program costs, including infrastructure and outreach, required to improve adherence. ${ }^{67}$ Given the high cost of the mt-sDNA test compared with FIT, the patient support program included with the mt-sDNA test would need to yield high participation levels, relative to FIT, for mt-sDNA test to be competitive. ${ }^{67}$

A recent analysis focusing on the latest ACS CRC screening recommendation concluded that screening initiation at age 45 years vs 50 years is likely to be cost effective, with costs/QALY gained of $\$ 33,900$ for colonoscopy and $\$ 7700$ for FIT.$^{66}$ However, substantially greater benefits and also cost savings could be realized if the same resources could instead be used to improve participation among unscreened older persons. ${ }^{66}$ It remains to be seen whether we can screen younger people and improve screening rates in older people, or whether we face resource constraints and trade-offs. 
The total budget effects of CRC screening depends on a screening program's costs balanced against CRC treatment costs averted, costs from an organized population management program, and the phase of implementation (initial launch vs steady state), because it can take years for screening programs to realize savings in averted CRC care. Program costs can be considerable. ${ }^{77,78}$ In the US, navigation for 1-time screening colonoscopy may be cost saving, and navigation for a program of repeated colonoscopic screening is estimated to be highly cost effective. ${ }^{79}$ A modeling study indicated that screening at ages 50-64 under commercial insurance in the US yields substantial clinical and economic benefits that accrue primarily at ages $\geq 65$ under Medicare. ${ }^{80}$

\section{Harms of Screening}

The shadow of the Telemark sigmoidoscopy study hung over the early years of CRC screening. ${ }^{81}$ In that study of modest sample size, screening decreased CRC incidence, but higher overall mortality was observed in the screening group (14\%) vs unscreened patients (9\%). More recent, larger, randomized trials have provided reassurance that the Telemark study results were an aberration. $^{74}$

The principal harms of CRC screening relate to the potential complications of lower endoscopy. A recent systematic review reported pooled risk estimates of $4 \%$ for perforation and $8 \%$ for major hemorrhage per 10,000 screening colonoscopies. ${ }^{12}$ The risks with polypectomy are higher. ${ }^{82}$ In a population-based study from California, the rates of myocardial infarction, stroke, and serious pulmonary events after colonoscopy were low and no higher than after low-risk comparator procedures, so they are unlikely to affect the benefit-to-risk balance of colonoscopy. ${ }^{82}$ 


\section{Emerging Screening Strategies}

Changes to screening paradigms could come from the development of new tests. Blood tests are widely adopted, evidenced by the frequent use of the prostate-specific antigen test to detect prostate cancer, despite the unenthusiastic recommendation from the USPSTF. ${ }^{83}$ In addition, disruptive enhancements could be developed for established strategies, such as colonoscopy or FIT. Finally, new visualization strategies, including next-generation capsule endoscopy, could be used.

Circulating tumor DNA (ctDNA), also called cell-free DNA or liquid biopsy, ${ }^{84}$ are sequences of DNA detected in the circulation derived from tumor cells undergoing apoptosis. Fragments of DNA with variants or mutations found in cancer cells can be specific markers of tumors. However, the number of mutant DNA fragments found in plasma varies among tumor types. ${ }^{85,86}$ Levels of ctDNA can indicate the overall tumor burden ${ }^{85,87,88}$ (higher levels correlating with larger or more advanced tumors), but some patients with advanced tumors do not have detectable ctDNA. ${ }^{85,89}$ Moreover, for any specific tumor type, it is not clear why some patients have detectable ctDNA and others do not. The number of ctDNA fragments can be as low as 1 single mutant fragment per $1 \mathrm{ml}$ plasma, so digital genomic technology with next-generation sequencing and massive parallel sequencing are used to amplify the mutant ctDNA fragments. These systems can be used to determine whether the mutated fragment of DNA came from a cancer cell or was a random error of DNA polymerase in a normal cell. ${ }^{84,90}$

Circulating tumor cells are intact tumor cells that can be purified from blood using physicochemical or cell surface molecules. Using a highly sensitive technique for ctDNA quantification and to avoid technical issues related to purification of circulating tumor cells, researchers found no samples to contain circulating tumor cells but no ctDNA. ${ }^{85}$ However, in many samples, ctDNA could be detected when circulating tumor cells were absent. ${ }^{85}$ Tests for ctDNA are 
therefore more promising for identification of patients with CRC.

For persons with a diagnosis of cancer, ctDNA analysis might be used to determine their prognoses or in surveillance for recurrence. In patients with stage $2 \mathrm{CRC}$, detection of ctDNA after surgery increased risk of recurrence 18 -fold compared with no detection of DNA. ${ }^{91}$ The assay for ctDNA also more accurately identified patients with stage 2 CRC who are candidates for adjuvant chemotherapy than did clinical characteristics. ${ }^{92}$ Increased levels of ctDNA preceded increased levels of carcinoembryonic antigen. ${ }^{92}$ ctDNA also provided clues into the mechanisms underlying resistance to EGFR blockade in patients who objectively responded to therapy but subsequently relapsed. ${ }^{85}$

Researchers identified a collection of 61 mutations or amplifications in 16 genes that can be used to screen for 8 cancers, including ovary, liver, stomach, pancreas, esophagus, colorectal, lung, or breast (the CancerSEEK panel) ${ }^{86}$ Because the test for ctDNA does not detect most early-stage tumors with a high level of sensitivity, researchers included in the test assays for 8 protein biomarkers that can be detected in blood. The threshold for a positive result was set high for each protein marker, to maximize specificity and avoid false-positive results, in recognition that each protein increases sensitivity by a small amount. In a case-control study of 1005 patients with stage 1-3 tumors and 812 individuals without cancer (controls), this test identified patients with cancer with $70 \%$ sensitivity and $>99 \%$ specificity; results ranged from $98 \%$ sensitivity in detection of ovarian and hepatocellular cancers to $33 \%$ in detection of breast cancer. This test identified patients with CRC with $66 \%$ sensitivity. ${ }^{86}$

These mutations and proteins are markers of several tumor types, so it is not clear how to follow up patients with positive results from this test. A machine-learning algorithm was able to localize the source of the cancer to 1 of 2 anatomic sites in a median of $83 \%$ of patients ${ }^{86}$. A 
prospective study is underway at the Geisinger Health Center, in collaboration with Johns Hopkins University, to evaluate levels of ctDNA and proteins in blood samples from 10,000 women, 65-75 years old (the DETECT trial). Subjects with 2 consecutive positive test results will be evaluated for the predicted site of neoplasia and undergo imaging analyses (https://www.geisinger.org/sites/detectstudy). Subjects will be followed for clinical signs of cancer for at least 2 years.

\section{Epigenetic markers}

Epigenetic changes are alterations that affect expression of mRNA or protein but not DNA sequences. Epigenetic changes include alterations in DNA methylation (increases or decreases at certain loci), in histones, and in translation of mRNAs via interactions with non-coding RNAs. ${ }^{93}$ Epigenetic markers could be used to predict disease progression or response to treatment, or in screening.

Changes in DNA methylation can alter gene expression. The average CRC cell has hundreds to thousands of abnormally methylated genes, ${ }^{93}$ based on methylome analyses. Some of these alter transcription of genes that contribute to tumorigenesis or tumor progression. ${ }^{94}$ A panel of markers might someday be used in screening for CRC. Although markers of abnormal methylation patterns have been associated with transformation and tumor development, methylation changes are heritable and can accumulate in aging and inflammatory conditions, compromising specificity.

An assay to detect changes in methylation at the septin9 gene in plasma samples has been approved by the FDA for CRC screening. The assay identifies patients with CRC with approximately $70 \%$ sensitivity, with a 10\%-20\% false-positive rate, so it may have limited practical utility.

Modification in histone proteins affects the 3-dimsional structure of nucleosomes and 
transcription of multiple genes. Technical limitations in assessing histone modifications limit our ability to determine whether histone modifications can be used to identify cancer cells. Exploratory studies have been performed, ${ }^{93,95}$ but further research is needed.

Approximately $80 \%$ of the genome is transcribed into non-coding RNAs, which include microRNAs and long non-coding RNAs. ${ }^{93}$ These RNA molecules are not transcribed into proteins, but regulate gene expression at the transcriptional and post-transcriptional level. Changes in miRNA levels and activities have been observed in cancer cells. MicroRNAs levels might be used as markers of cancer, due to their stability, small size, and hairpin-loop structure that protects them from degradation. It is easy to extract microRNAs from specimens including blood, stool, and saliva, and microRNAs are secreted by tumors into the circulation and gastrointestinal tract. ${ }^{93,96}$ However, lack of standardization in measurement has hampered their practical application. Changes in levels of individual microRNAs and panels of miRNAs have been associated with different cancers, but these assays are not ready for use in the clinic.$^{97}$

Levels of specific proteins have also been associated with cancer, ${ }^{97}$ but no 1 protein or panel of proteins identifies patients with cancer with sufficient levels of sensitivity for clinical use. Combination assays for specific proteins and ctDNA might increase the sensitivity of tumor detection, with higher levels of specificity.

Volatile organic compounds (VOCs) are metabolites that can be detected by smell. VOC patterns are altered in stool, urine, and breath samples of patients with cancer, and a specially trained Labrador retriever was able identify patients with CRC. ${ }^{98,99}$ VOCs have been explored as biomarkers of CRC in small, case-control studies. ${ }^{100}$ In a gas mixture, VOCs are analyzed by gas chromatography-mass spectrometry, and researchers have developed a sensor array called an electronic nose. With a pattern detector, the individual components cannot be determined. ${ }^{99,100}$ 
Studies are needed to validate VOCs as biomarkers of CRC, as well as to standardize analytic techniques, determine reproducibility of assays, and identify potential confounding factors such as diet, microbiome, and medication use.

\section{Improving FIT, colonoscopy and capsules}

The FIT is used in CRC screening programs worldwide. Most FITs approved by the FDA are qualitative, but quantitative FITs have well-documented merits. ${ }^{21}$ It is possible to combine quantitative FITs with basic demographic information to create a smarter FIT, with greater predictive power for advanced neoplasia. ${ }^{101}$ The combination of fecal hemoglobin concentration and patient age and sex identified patients with advanced neoplasia with positive-predictive values that ranged from $21 \%$ to $76 \%$ and an 11 -fold variation in advanced neoplasia risk across categories. ${ }^{102}$ Such approaches are advantageous because they capitalize on existing screening infrastructures, and allow prioritization of referrals to colonoscopy.

Colonoscopy is the final common pathway of all CRC screening tests, and arguably the most effective single-application method for preventing CRC. Its major drawbacks are its operator dependency, reflected in the inverse association between adenoma detection rate and post-colonoscopy CRC risk, its significant burden to patients, and its high cost. ${ }^{103,104}$ Strategies to improve colonoscopy include adjuncts to increase mucosal exposure (cap, Endocuff, AmplifEye, EndoRings, G-EYE), technologies that enhance imaging (dye-based chromoendoscopy and electronic chromoendoscopy, including NBI, FICE, iScan, BLI), wider viewing angles (FUSE, Saneso $360^{\circ}$ system), and non-device techniques (water-based colonoscopy, dynamic position changes, second look in the proximal colon). Most mucosal exposure devices and chromoendoscopy have overall positive effects on neoplasia detection. ${ }^{105}$, 
${ }^{106}$ A new methylene blue-MMX oral preparation that is pending FDA approval might offer practical advantages over traditional dye-based chromoendoscopy. ${ }^{107}$ It is not clear whether these adjuncts are more helpful to low-level or high-level detectors, or whether they offer significant advantages over non-device interventions, such as second look in the right colon or water-based methods. ${ }^{106,108}$ To optimize CRC screening, we need to focus on improving performance in lowlevel detectors, because lower detection provides less protection against CRC, and because improved detection of diminutive lesions by high-level detectors is of uncertain clinical benefit.

Available colon capsules are passive viewing devices with applications that are limited to patients with incomplete colonoscopy or who decline other screening tests. ${ }^{109}$ The required arduous colon preparation is a limitation. However, the technology is advancing rapidly, including magnetically controlled or self-propelled capsules. ${ }^{110}$ Reliable optical biopsy and therapeutic capabilities could change paradigms.

\section{Future Directions}

The maximum preventable fraction of CRC cases and deaths that screening can achieve is probably high, but it is not clear how high (Figure 1A). In theory, frequent non-invasive monitoring could detect most incipient CRCs, or at worst, CRC at an early stage. On the other hand, accurate identification of low-risk colorectums and successful clearance of all relevant neoplasia even in highrisk colorectums could allow for relatively infrequent re-testing, given the long dwell-times from polyp to CRC.

The demise of screening colonoscopy has been predicted almost from its inception. It has not happened. This could change quickly depending on innovations around non-invasive alternatives, and how well they are accepted by patients. All CRC screening roads ultimately lead to colonoscopy, 
and colonoscopies prevent CRC because they include polypectomy, so it is the responsibility of endoscopists to perform colonoscopies with skill (Figure 1A)—whether during primary screening, follow-up of non-invasive screening test results, surveillance, or symptom evaluation.

Artificial intelligence (AI) could revolutionize screening in general, and endoscopy specifically. ${ }^{111,112}$ Computer-aided detection and histologic diagnosis systems are available and have shown promising results. ${ }^{113-116}$ However, adequate mucosal exposure and lesion resection will remain operator dependent. The most immediate goal is developing a real-time colonoscopy AI system that combines high detection sensitivity, high characterization accuracy, and fast processing time. However, AI-assisted colonoscopy could go further-if AI systems could reliably rate the adequacy of inspection and lesion resection, and provide real-time feedback to ensure adequate performance (incompletely visualized segment—recommend re-examination; residual polyp at margin—recommend resection and re-examination), it might be possible to certify a colonoscopy as: excellent visualization, all relevant lesions detected and removed. This might provide confidence to prolong screening and surveillance intervals. Such a paradigm could resolve the conundrum of the high polyp detector, in which patients who are presumably at low CRC risk after multiple successful polypectomies are surveyed intensively unnecessarily, precisely because of polyp multiplicity.

Regardless of screening strategy, patient participation will always be a key determinant of success. This is a social and behavioral challenge, as screening is a personal choice that is ideally based on informed decision making. Organized programs have advantages over opportunistic screening. However, the full potential benefit of outreach, navigation, and rapidly evolving digital innovations, such as smart phone applications, have not yet been realized. In the US, a national CRC screening program could be the next big step, but that is a major challenge 
given the healthcare system. The effects of commercial incentives on screening participation, such as the aggressive direct to consumer and primary-care, physician-centered campaigns promoting the mt-sDNA test, are not completely clear. We will need to determine the effects of such incentives on test choice, in addition to considerations based on test performance characteristics, interval, cost and acceptability by patients.

There is evidence for overutilization and underutilization of screening and surveillance. Risk stratification and personalized screening could optimize outcomes while making the best use of resources. ${ }^{101}$ Although it is not clear whether other guidelines will follow the ACS recommendation to lower the CRC screening initiation age to 45 years, the recommendation could be replaced by a sophisticated risk-stratification approach that is based on multiple factors. For many older patients, the risks of screening and surveillance outweigh the benefits, but screening of some older patients might be warranted.

CRC is a prime example of a public health success. We should be proud of the research that has brought us here, and of what we can do for the population today. As we strive to do better, we must not compromise the gains that can be achieved with current paradigms. We can envision sophisticated strategies for risk stratification and personalization, and complex quality metrics beyond the adenoma detect rate, as well as hybrid screening strategies that change over the course of life. However, efficacy in the ideal setting with optimal implementation might be different from effectiveness in the messy real world (see Figure 1). Highly efficacious strategies that are impractical to implement could harm screening participation, resulting in lower overall impact on CRC outcomes. On the other hand, sophisticated new strategies that harness technological innovation and the growing understanding of factors motivating human behavior could be revolutionary. 


\section{Figure 1. Considerations for CRC screening.}

1a) Even with new screening tests, colonoscopy with polypectomy is likely to remain the cornerstone of CRC prevention. We must ensure skillful inspection, lesion characterization, and lesion removal, whether in primary screening, follow-up of non-invasive screening test results, surveillance, or symptom evaluation. 1b) Risk-stratification and personalization, additional quality metrics beyond the adenoma detection rate, or other innovations such as hybrid screening programs that coalesce to produce increasingly sophisticated and effective screening strategies must avoid excessive complexity, resource-consumption, and other limitations that could decrease screening participation and inadvertently harm CRC control efforts. 1c) New strategies that are efficacious and practical to implement could revolutionize CRC screening. 


\section{References}

1. White A, Thompson TD, White MC, et al. Cancer Screening Test Use - United States, 2015. MMWR. Morbidity and Mortality Weekly Report 2017;66:201-206.

2. Meester RG, Doubeni CA, Lansdorp-Vogelaar I, et al. Colorectal cancer deaths attributable to nonuse of screening in the United States. Ann Epidemiol 2015;25:208-213 e1.

3. Siegel RL, Miller KD, Jemal A. Cancer statistics, 2019. CA: a cancer journal for clinicians 2019;69:7-34.

4. Edwards BK, Ward E, Kohler BA, et al. Annual report to the nation on the status of cancer, 1975-2006, featuring colorectal cancer trends and impact of interventions (risk factors, screening, and treatment) to reduce future rates. Cancer 2010;116:544-73.

5. Zauber AG, Winawer SJ, O'Brien MJ, et al. Colonoscopic polypectomy and long-term prevention of colorectal-cancer deaths. The New England Journal of Medicine 2012;366:687-696.

6. Ransohoff DF, Lang CA. Screening for colorectal cancer with the fecal occult blood test: a background paper. American College of Physicians [see comments]. Annals of Internal Medicine 1997;126:811-22.

7. Kronborg O, Jorgensen OD, Fenger C, et al. Randomized study of biennial screening with a faecal occult blood test: results after nine screening rounds. Scand J Gastroenterol 2004;39:846-51.

8. Scholefield JH, Moss SM, Mangham CM, et al. Nottingham trial of faecal occult blood testing for colorectal cancer: a 20-year follow-up. Gut 2012;61:1036-40.

9. Shaukat A, Mongin SJ, Geisser MS, et al. Long-Term Mortality after Screening for Colorectal Cancer. New England Journal of Medicine 2013;369:1106-1114.

10. Lindholm E, Brevinge H, Haglind E. Survival benefit in a randomized clinical trial of faecal occult blood screening for colorectal cancer. The British Journal of Surgery 2008;95:1029-1036.

11. Faivre J, Dancourt V, Lejeune C, et al. Reduction in colorectal cancer mortality by fecal occult blood screening in a French controlled study. Gastroenterology 2004;126:1674-1680.

12. Lin JS, Piper MA, Perdue LA, et al. Screening for Colorectal Cancer: A Systematic Review for the U.S. Preventive Services Task Force. Evidence Synthesis No. 135. Rockville, MD: Agency for Healthcare Research and Quality, 2015.

13. Mandel JS, Church TR, Bond JH, et al. The effect of fecal occult-blood screening on the incidence of colorectal cancer. New England Journal of Medicine 2000;343:16031607.

14. Allison JE, Tekawa IS, Ransom LJ, et al. A comparison of fecal occult-blood tests for colorectal-cancer screening. N Engl J Med 1996;334:155-9.

15. Levi Z, Birkenfeld S, Vilkin A, et al. A higher detection rate for colorectal cancer and advanced adenomatous polyp for screening with immunochemical fecal occult blood test than guaiac fecal occult blood test, despite lower compliance rate. A prospective, controlled, feasibility study. International Journal of Cancer 2011;128:2415-2424. 
16. Vart G, Banzi R, Minozzi S. Comparing participation rates between immunochemical and guaiac faecal occult blood tests: a systematic review and meta-analysis. Preventive Medicine 2012;55:87-92.

17. Zorzi M, Fedeli U, Schievano E, et al. Impact on colorectal cancer mortality of screening programmes based on the faecal immunochemical test. Gut 2015;64:78490.

18. Giorgi Rossi P, Vicentini M, Sacchettini C, et al. Impact of Screening Program on Incidence of Colorectal Cancer: A Cohort Study in Italy. Am J Gastroenterol 2015;110:1359-66.

19. Chiu HM, Chen SL, Yen AM, et al. Effectiveness of fecal immunochemical testing in reducing colorectal cancer mortality from the One Million Taiwanese Screening Program. Cancer 2015;121:3221-9.

20. Lee JK, Liles EG, Bent S, et al. Accuracy of fecal immunochemical tests for colorectal cancer: systematic review and meta-analysis. Annals of Internal Medicine 2014;160:171.

21. Robertson DJ, Lee JK, Boland CR, et al. Recommendations on Fecal Immunochemical Testing to Screen for Colorectal Neoplasia: A Consensus Statement by the US MultiSociety Task Force on Colorectal Cancer. Gastroenterology 2017;152:1217-1237 e3.

22. Goel A, Boland CR. Epigenetics of colorectal cancer. Gastroenterology 2012;143:1442-1460 e1.

23. Imperiale TF, Ransohoff DF, Itzkowitz SH, et al. Multitarget stool DNA testing for colorectal-cancer screening. The New England Journal of Medicine 2014;370:12871297.

24. Schoen RE, Pinsky PF, Weissfeld JL, et al. Colorectal-cancer incidence and mortality with screening flexible sigmoidoscopy. The New England Journal of Medicine 2012;366:2345-2357.

25. Atkin W, Wooldrage K, Parkin DM, et al. Long term effects of once-only flexible sigmoidoscopy screening after 17 years of follow-up: the UK Flexible Sigmoidoscopy Screening randomised controlled trial. Lancet (London, England) 2017;389:12991311.

26. Holme 0, Loberg M, Kalager M, et al. Long-Term Effectiveness of Sigmoidoscopy Screening on Colorectal Cancer Incidence and Mortality in Women and Men: A Randomized Trial. Ann Intern Med 2018;168:775-782.

27. Segnan N, Armaroli P, Bonelli L, et al. Once-only sigmoidoscopy in colorectal cancer screening: follow-up findings of the Italian Randomized Controlled Trial--SCORE. Journal of the National Cancer Institute 2011;103:1310-1322.

28. Atkin WS, Edwards R, Kralj-Hans I, et al. Once-only flexible sigmoidoscopy screening in prevention of colorectal cancer: a multicentre randomised controlled trial. Lancet 2010;375:1624-33.

29. Holme O, Schoen RE, Senore C, et al. Effectiveness of flexible sigmoidoscopy screening in men and women and different age groups: pooled analysis of randomised trials. Bmj 2017;356:i6673.

30. Bretthauer M, Kaminski MF, Loberg M, et al. Population-Based Colonoscopy Screening for Colorectal Cancer: A Randomized Clinical Trial. JAMA Intern Med 2016;176:894-902. 
31. Kaminski MF, Bretthauer M, Zauber AG, et al. The NordICC Study: rationale and design of a randomized trial on colonoscopy screening for colorectal cancer. Endoscopy 2012;44:695-702.

32. Kahi CJ, Imperiale TF, Juliar BE, et al. Effect of screening colonoscopy on colorectal cancer incidence and mortality. Clin Gastroenterol Hepatol 2009;7:770-5; quiz 711.

33. Manser CN, Bachmann LM, Brunner J, et al. Colonoscopy screening markedly reduces the occurrence of colon carcinomas and carcinoma-related death: a closed cohort study. Gastrointest Endosc 2012;76:110-7.

34. Doubeni CA, Corley DA, Quinn VP, et al. Effectiveness of screening colonoscopy in reducing the risk of death from right and left colon cancer: a large community-based study. Gut 2018;67:291-298.

35. Kahi CJ, Pohl H, Myers LJ, et al. Colonoscopy and Colorectal Cancer Mortality in the Veterans Affairs Health Care System: A Case-Control Study. Annals of Internal Medicine 2018.

36. Brenner H, Chang-Claude J, Jansen L, et al. Reduced risk of colorectal cancer up to 10 years after screening, surveillance, or diagnostic colonoscopy. Gastroenterology 2014;146:709-17.

37. Nishihara R, Wu K, Lochhead P, et al. Long-term colorectal-cancer incidence and mortality after lower endoscopy. The New England Journal of Medicine 2013;369:1095-1105.

38. Baxter NN, Warren JL, Barrett MJ, et al. Association between colonoscopy and colorectal cancer mortality in a US cohort according to site of cancer and colonoscopist specialty. Journal of Clinical Oncology: Official Journal of the American Society of Clinical Oncology 2012;30:2664-2669.

39. Singh H, Nugent $Z$, Demers AA, et al. The reduction in colorectal cancer mortality after colonoscopy varies by site of the cancer. Gastroenterology 2010;139:1128-37.

40. Doubeni CA, Weinmann S, Adams K, et al. Screening colonoscopy and risk for incident late-stage colorectal cancer diagnosis in average-risk adults: a nested casecontrol study. Ann Intern Med 2013;158:312-20.

41. Cotterchio M, Manno M, Klar N, et al. Colorectal screening is associated with reduced colorectal cancer risk: a case-control study within the population-based Ontario Familial Colorectal Cancer Registry. Cancer Causes Control 2005;16:865-75.

42. Baxter NN, Goldwasser MA, Paszat LF, et al. Association of colonoscopy and death from colorectal cancer. Ann Intern Med 2009;150:1-8.

43. Zhao S, Wang S, Pan P, et al. Magnitude, Risk Factors, and Factors Associated With Adenoma Miss Rate of Tandem Colonoscopy: A Systematic Review and Metaanalysis. Gastroenterology 2019;156:1661-1674.e11.

44. Ijspeert JEG, Tutein Nolthenius CJ, Kuipers EJ, et al. CT-Colonography vs. Colonoscopy for Detection of High-Risk Sessile Serrated Polyps. The American Journal of Gastroenterology 2016;111:516-522.

45. Screening for colorectal cancer: U.S. Preventive Services Task Force recommendation statement. Ann Intern Med 2008;149:627-37.

46. Church TR, Wandell M, Lofton-Day C, et al. Prospective evaluation of methylated SEPT9 in plasma for detection of asymptomatic colorectal cancer. Gut 2014;63:31725. 
47. Potter NT, Hurban P, White MN, et al. Validation of a real-time PCR-based qualitative assay for the detection of methylated SEPT9 DNA in human plasma. Clinical Chemistry 2014;60:1183-1191.

48. Zhang $\mathrm{M}, \mathrm{He} \mathrm{Y}$, Zhang $\mathrm{X}$, et al. A pooled analysis of the diagnostic efficacy of plasmic methylated septin- 9 as a novel biomarker for colorectal cancer. Biomed Rep 2017;7:353-360.

49. Rex DK, Adler SN, Aisenberg J, et al. Accuracy of capsule colonoscopy in detecting colorectal polyps in a screening population. Gastroenterology 2015;148:948-957 e2.

50. Levin TR, Corley DA, Jensen CD, et al. Effects of Organized Colorectal Cancer Screening on Cancer Incidence and Mortality in a Large Community-Based Population. Gastroenterology 2018;155:1383-1391.e5.

51. Cooper GS, Markowitz SD, Chen Z, et al. Evaluation of Patients with an Apparent False Positive Stool DNA Test: The Role of Repeat Stool DNA Testing. Dig Dis Sci 2018;63:1449-1453.

52. Pooler BD, Kim DH, Weiss JM, et al. Colorectal Polyps Missed with Optical Colonoscopy Despite Previous Detection and Localization with CT Colonography. Radiology 2016;278:422-9.

53. Dominitz JA, Robertson DJ, Ahnen DJ, et al. Colonoscopy vs. Fecal Immunochemical Test in Reducing Mortality From Colorectal Cancer (CONFIRM): Rationale for Study Design. The American Journal of Gastroenterology 2017;112:1736-1746.

54. Quintero E, Castells A, Bujanda L, et al. Colonoscopy versus fecal immunochemical testing in colorectal-cancer screening. N Engl J Med 2012;366:697-706.

55. SCREESCO - Screening of Swedish Colons.

56. Young GP, Senore C, Mandel JS, et al. Recommendations for a step-wise comparative approach to the evaluation of new screening tests for colorectal cancer. Cancer 2016;122:826-39.

57. Stoop EM, de Haan MC, de Wijkerslooth TR, et al. Participation and yield of colonoscopy versus non-cathartic CT colonography in population-based screening for colorectal cancer: a randomised controlled trial. Lancet Oncol 2012;13:55-64.

58. Duncan A, Turnbull D, Wilson C, et al. Behavioural and demographic predictors of adherence to three consecutive faecal occult blood test screening opportunities: A population study. BMC Public Health 2014;14.

59. Lo SH, Halloran S, Snowball J, et al. Colorectal cancer screening uptake over three biennial invitation rounds in the English bowel cancer screening programme. Gut 2015;64:282-91.

60. Bibbins-Domingo K, Grossman DC, Curry SJ, et al. Screening for Colorectal Cancer: US Preventive Services Task Force Recommendation Statement. Jama 2016;315:2564-75.

61. Knudsen AB, Zauber AG, Rutter CM, et al. Estimation of Benefits, Burden, and Harms of Colorectal Cancer Screening Strategies: Modeling Study for the US Preventive Services Task Force. Jama 2016;315:2595-609.

62. Wolf AMD, Fontham ETH, Church TR, et al. Colorectal cancer screening for averagerisk adults: 2018 guideline update from the American Cancer Society. CA Cancer J Clin 2018;68:250-281. 
63. Meester RGS, Peterse EFP, Knudsen AB, et al. Optimizing colorectal cancer screening by race and sex: Microsimulation analysis II to inform the American Cancer Society colorectal cancer screening guideline. Cancer 2018;124:2974-2985.

64. Peterse EFP, Meester RGS, Siegel RL, et al. The impact of the rising colorectal cancer incidence in young adults on the optimal age to start screening: Microsimulation analysis I to inform the American Cancer Society colorectal cancer screening guideline. Cancer 2018;124:2964-2973.

65. Zauber A, Knudsen A, Rutter CM, et al. Evaluating the Benefits and Harms of Colorectal Cancer Screening Strategies: A Collaborative Modeling Approach. AHRQ Publication No. 14-05203-EF-2 2015.

66. Ladabaum U, Mannalithara A, Meester RGS, et al. Cost-effectiveness and National Effects of Initiating Colorectal Cancer Screening for Average-risk Persons at Age 45 Years Instead of 50 Years. Gastroenterology 2019.

67. Ladabaum U, Mannalithara A. Comparative Effectiveness and Cost Effectiveness of a Multitarget Stool DNA Test to Screen for Colorectal Neoplasia. Gastroenterology 2016;151:427-439.e6.

68. Pignone M, Saha S, Hoerger T, et al. Cost-effectiveness analyses of colorectal cancer screening: a systematic review for the U.S. Preventive Services Task Force. Ann Intern Med 2002;137:96-104.

69. Lansdorp-Vogelaar I, Knudsen AB, Brenner H. Cost-effectiveness of colorectal cancer screening. Epidemiol Rev 2011;33:88-100.

70. Ran T, Cheng CY, Misselwitz B, et al. Cost-Effectiveness of Colorectal Cancer Screening Strategies-A Systematic Review. Clin Gastroenterol Hepatol 2019.

71. International Agency for Research on Cancer. World Health Organization. GLOBOCAN. Accessed at http://globocan.iarc.fr/ on April 26, 2019.

72. Ginsberg GM, Lim SS, Lauer JA, et al. Prevention, screening and treatment of colorectal cancer: a global and regional generalized cost effectiveness analysis. Cost Eff Resour Alloc 2010;8:2.

73. Ladabaum U, Song K. Projected national impact of colorectal cancer screening on clinical and economic outcomes and health services demand. Gastroenterology 2005;129:1151-62.

74. Swartz AW, Eberth JM, Josey MJ, et al. Re-analysis of All-Cause Mortality in the U.S. Preventive Services Task Force 2016 Evidence Report on Colorectal Cancer Screening. Ann Intern Med 2017.

75. Parekh M, Fendrick AM, Ladabaum U. As tests evolve and costs of cancer care rise: reappraising stool-based screening for colorectal neoplasia. Aliment Pharmacol Ther 2008;27:697-712.

76. Lansdorp-Vogelaar I, van Ballegooijen M, Zauber AG, et al. Effect of rising chemotherapy costs on the cost savings of colorectal cancer screening. J Natl Cancer Inst 2009;101:1412-22.

77. Subramanian S, Tangka FK, Hoover S, et al. Costs of planning and implementing the CDC's Colorectal Cancer Screening Demonstration Program. Cancer 2013;119 Suppl 15:2855-62.

78. Subramanian S, Tangka FK, Hoover S, et al. Clinical and programmatic costs of implementing colorectal cancer screening: evaluation of five programs. Eval Program Plann 2011;34:147-53. 
79. Ladabaum U, Mannalithara A, Jandorf L, et al. Cost-Effectiveness of Patient Navigation to Increase Adherence with Screening Colonoscopy Among Minority Individuals. Cancer 2015;121:1088-97.

80. Ladabaum U, Mannalithara A, Brill JV, et al. Contrasting Effectiveness and CostEffectiveness of Colorectal Cancer Screening Under Commercial Insurance vs. Medicare. Am J Gastroenterol 2018.

81. Thiis-Evensen E, Hoff GS, Sauar J, et al. Population-based surveillance by colonoscopy: effect on the incidence of colorectal cancer. Telemark Polyp Study I. Scand J Gastroenterol 1999;34:414-20.

82. Wang L, Mannalithara A, Singh G, et al. Low Rates of Gastrointestinal and NonGastrointestinal Complications for Screening or Surveillance Colonoscopies in a Population-Based Study. Gastroenterology 2018;154:540-555.e8.

83. Grossman DC, Curry SJ, Owens DK, et al. Screening for Prostate Cancer: US Preventive Services Task Force Recommendation Statement. Jama 2018;319:19011913.

84. Corcoran RB, Chabner BA. Cell-free DNA Analysis in Cancer. N Engl J Med 2019;380:501-502.

85. Bettegowda C, Sausen M, Leary RJ, et al. Detection of circulating tumor DNA in earlyand late-stage human malignancies. Science Translational Medicine 2014;6:224ra24.

86. Cohen JD, Li L, Wang Y, et al. Detection and localization of surgically resectable cancers with a multi-analyte blood test. Science 2018;359:926-930.

87. Dawson S-J, Tsui DWY, Murtaza M, et al. Analysis of circulating tumor DNA to monitor metastatic breast cancer. New England Journal of Medicine 2013;368:1199209.

88. Diehl F, Schmidt K, Choti MA, et al. Circulating mutant DNA to assess tumor dynamics. Nature Medicine 2008;14:985-90.

89. Heitzer E, Auer M, Hoffmann EM, et al. Establishment of tumor-specific copy number alterations from plasma DNA of patients with cancer. International Journal of Cancer 2013;133:346-56.

90. Kinde I, $\mathrm{Wu}$ J, Papadopoulos $\mathrm{N}$, et al. Detection and quantification of rare mutations with massively parallel sequencing. Proc Natl Acad Sci U S A 2012;108:9530-5.

91. Tie J, Wang Y, Tomasetti C, et al. Circulating tumor DNA analysis detects minimal residual disease and predicts recurrence in patients with stage II colon cancer. Sci Transl Med 2016;8.

92. Baier M, Calonge N, Cutter G, et al. Validity of self-reported colorectal cancer screening behavior. Cancer Epidemiology, 2000 Feb.

93. Okugawa Y, Grady WM, Goel A. Epigenetic Alterations in Colorectal Cancer: Emerging Biomarkers. Gastroenterology 2015;149:1204-1225.e12.

94. Grady WM, Myeroff LL, Swinler SE, et al. Mutational inactivation of transforming growth factor beta receptor type II in microsatellite stable colon cancers. Cancer Research 1999;59:320-324.

95. Benard A, Goossens-Beumer IJ, van Hoesel AQ, et al. Prognostic value of polycomb proteins EZH2, BMI1 and SUZ12 and histone modification H3K27me3 in colorectal cancer. PLoS One 2014;9:e108265.

96. Yiu AJ, Yiu CY. Biomarkers in Colorectal Cancer. Anticancer Res 2016;36:1093-102. 
97. Nikolaou S, Qiu S, Fiorentino F, et al. Systematic review of blood diagnostic markers in colorectal cancer. Tech Coloproctol 2018;22:481-498.

98. Sonoda H, Kohnoe S, Yamazato T, et al. Colorectal cancer screening with odour material by canine scent detection. Gut 2011;60:814-9.

99. de Boer NK, de Meij TG, Oort FA, et al. The scent of colorectal cancer: detection by volatile organic compound analysis. Clin Gastroenterol Hepatol 2014;12:1085-9.

100. Bosch S, Berkhout DJ, Ben Larbi I, et al. Fecal volatile organic compounds for early detection of colorectal cancer: where are we now? J Cancer Res Clin Oncol 2019;145:223-234.

101. Robertson DJ, Ladabaum U. Opportunities and Challenges in Moving From Current Guidelines to Personalized Colorectal Cancer Screening. Gastroenterology 2019;156:904-917.

102. Auge JM, Pellise M, Escudero JM, et al. Risk stratification for advanced colorectal neoplasia according to fecal hemoglobin concentration in a colorectal cancer screening program. Gastroenterology 2014;147:628-636 e1.

103. Corley DA, Jensen CD, Marks AR, et al. Adenoma detection rate and risk of colorectal cancer and death. N Engl J Med 2014;370:1298-306.

104. Kaminski MF, Regula J, Kraszewska E, et al. Quality indicators for colonoscopy and the risk of interval cancer. N Engl J Med 2010;362:1795-803.

105. Rex DK, Repici A, Gross SA, et al. High-definition colonoscopy versus Endocuff versus EndoRings versus full-spectrum endoscopy for adenoma detection at colonoscopy: a multicenter randomized trial. Gastrointest Endosc 2018;88:335-344 e2.

106. Facciorusso A, Del Prete V, Buccino RV, et al. Comparative Efficacy of Colonoscope Distal Attachment Devices in Increasing Rates of Adenoma Detection: A Network Meta-analysis. Clin Gastroenterol Hepatol 2018;16:1209-1219 e9.

107. Repici A, Wallace MB, East JE, et al. Efficacy of Per-oral Methylene Blue Formulation for Screening Colonoscopy. Gastroenterology 2019.

108. Williet N, Tournier Q, Vernet C, et al. Effect of Endocuff-assisted colonoscopy on adenoma detection rate: meta-analysis of randomized controlled trials. Endoscopy 2018;50:846-860.

109. Rex DK, Boland CR, Dominitz JA, et al. Colorectal Cancer Screening: Recommendations for Physicians and Patients From the U.S. Multi-Society Task Force on Colorectal Cancer. Gastroenterology 2017;153:307-323.

110. Gu H, Zheng H, Cui X, et al. Maneuverability and safety of a magnetic-controlled capsule endoscopy system to examine the human colon under real-time monitoring by colonoscopy: a pilot study (with video). Gastrointest Endosc 2017;85:438-443.

111. Alagappan M, Brown JRG, Mori Y, et al. Artificial intelligence in gastrointestinal endoscopy: The future is almost here. World J Gastrointest Endosc 2018;10:239249.

112. Ruffle JK, Farmer AD, Aziz Q. Artificial Intelligence-Assisted GastroenterologyPromises and Pitfalls. Am J Gastroenterol 2019;114:422-428.

113. Byrne MF, Chapados N, Soudan F, et al. Real-time differentiation of adenomatous and hyperplastic diminutive colorectal polyps during analysis of unaltered videos of standard colonoscopy using a deep learning model. Gut 2019;68:94-100. 
114. Byrne MF, Shahidi N, Rex DK. Will Computer-Aided Detection and Diagnosis Revolutionize Colonoscopy? Gastroenterology 2017;153:1460-1464 e1.

115. Mori Y, Kudo SE, Misawa M, et al. Real-Time Use of Artificial Intelligence in Identification of Diminutive Polyps During Colonoscopy: A Prospective Study. Ann Intern Med 2018;169:357-366.

116. Zhang X, Chen F, Yu T, et al. Real-time gastric polyp detection using convolutional neural networks. PLoS One 2019;14:e0214133.

117. Kahi CJ, Li X, Eckert GJ, et al. High colonoscopic prevalence of proximal colon serrated polyps in average-risk men and women. Gastrointest Endosc 2012;75:51520.

118. Kahi CJ, Hewett DG, Norton DL, et al. Prevalence and variable detection of proximal colon serrated polyps during screening colonoscopy. Clin Gastroenterol Hepatol 2011;9:42-6.

119. Hetzel JT, Huang CS, Coukos JA, et al. Variation in the detection of serrated polyps in an average risk colorectal cancer screening cohort. Am J Gastroenterol 2010;105:2656-64.

120. Hazewinkel Y, de Wijkerslooth TR, Stoop EM, et al. Prevalence of serrated polyps and association with synchronous advanced neoplasia in screening colonoscopy. Endoscopy 2014;46:219-24.

121. de Wijkerslooth TR, Stoop EM, Bossuyt PM, et al. Differences in proximal serrated polyp detection among endoscopists are associated with variability in withdrawal time. Gastrointest Endosc 2013;77:617-23.

122. Crockett SD, Gourevitch RA, Morris M, et al. Endoscopist factors that influence serrated polyp detection: a multicenter study. Endoscopy 2018;50:984-992.

123. Anderson JC, Butterly LF, Weiss JE, et al. Providing data for serrated polyp detection rate benchmarks: an analysis of the New Hampshire Colonoscopy Registry. Gastrointest Endosc 2017;85:1188-1194.

124. Abdeljawad K, Vemulapalli KC, Kahi CJ, et al. Sessile serrated polyp prevalence determined by a colonoscopist with a high lesion detection rate and an experienced pathologist. Gastrointest Endosc 2015;81:517-24.

125. Kim DH, Matkowskyj KA, Lubner MG, et al. Serrated Polyps at CT Colonography: Prevalence and Characteristics of the Serrated Polyp Spectrum. Radiology 2016;280:455-63.

126. Lieberman D, Ladabaum U, Cruz-Correa M, et al. Screening for Colorectal Cancer and Evolving Issues for Physicians and Patients: A Review. Jama 2016;316:2135-2145. 


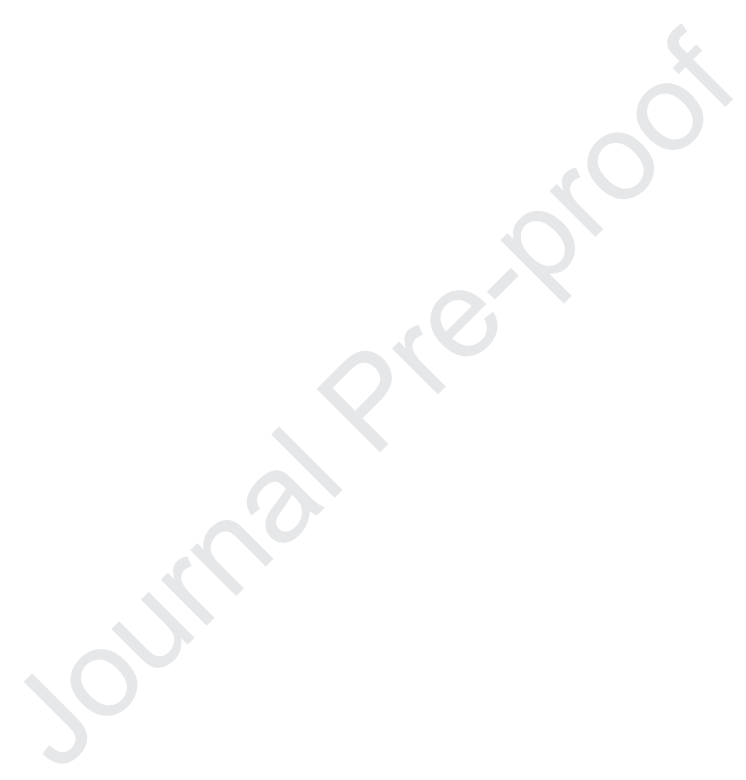




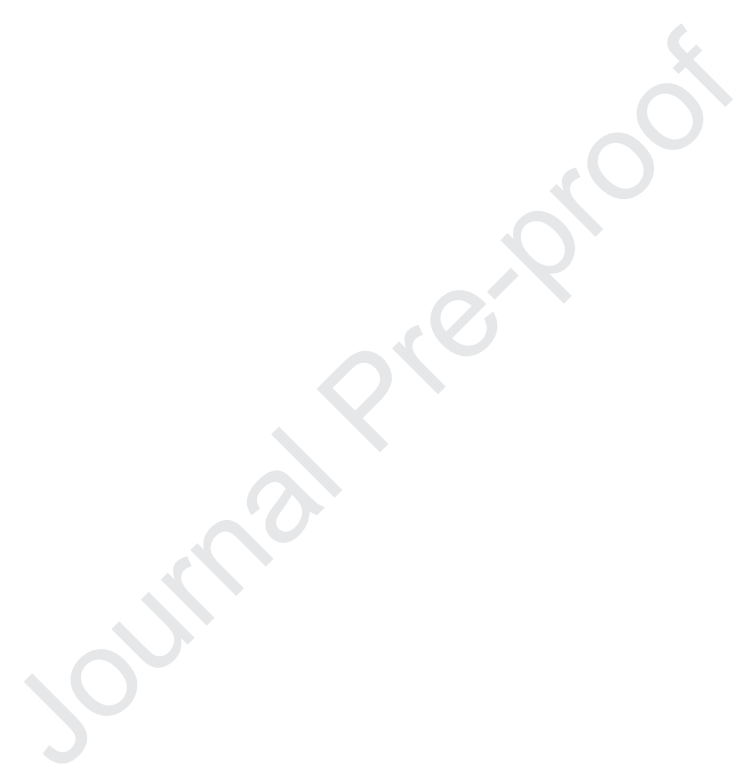


Table 1. Effects of Screening on CRC Incidence and Mortality

\begin{tabular}{|c|c|c|c|c|}
\hline Screening Test & Evidence Sources & $\begin{array}{l}\text { Reduction in } \\
\text { CRC Incidence }\end{array}$ & $\begin{array}{l}\text { Reduction in } \\
\text { CRC Mortality }\end{array}$ & $\begin{array}{l}\text { Reduction in } \\
\text { Overall Mortality }\end{array}$ \\
\hline \multicolumn{5}{|l|}{ stool-based tests } \\
\hline $\mathrm{gFOBT}^{7-12}$ & randomized controlled trials & $17 \%-20 \%$ & $9 \%-22 \%$ & $\begin{array}{c}\text { no benefit } \\
\text { demonstrated }\end{array}$ \\
\hline $\mathrm{FIT}^{17-19}$ & $\begin{array}{l}\text { observational studies, } \\
\text { test characteristic studies }\end{array}$ & $10 \%$ & $22 \%-62 \%$ & unknown \\
\hline FIT-DNA (mt-sDNA test) & $\begin{array}{l}\text { test characteristic studies, compared } \\
\text { to fit and colonoscopy }\end{array}$ & unknown & unknown & unknown \\
\hline \multicolumn{5}{|l|}{ direct visualization tests } \\
\hline flexible sigmoidoscopy ${ }^{24-27,74}$ & randomized controlled trials & $\begin{array}{c}\text { intent to treat: } \\
27 \%(17 \%-23 \%) \\
\text { per protocol: } \\
31 \%-33 \%\end{array}$ & $\begin{array}{c}\text { intent to treat: } \\
21 \%(22 \%- \\
31 \%) \\
\text { per protocol: } \\
38 \%-43 \%\end{array}$ & $\begin{array}{c}2 \%-4 \% \text { in } \\
\text { individual } \\
\text { studies; } 2.5 \% \text { in } \\
\text { meta-analysis }\end{array}$ \\
\hline colonoscopy $^{32-42}$ & observational studies & $\begin{array}{c}\text { cohort: } 40 \%- \\
69 \% \\
\text { case-control: } \\
31 \%-91 \%\end{array}$ & $\begin{array}{l}\text { cohort: } 29 \%- \\
88 \% \\
\text { case-control: } \\
60 \%-70 \%\end{array}$ & unknown \\
\hline CTC & test characteristic studies & unknown & unknown & unknown \\
\hline
\end{tabular}

gFOBT guaiac fecal occult blood test, FIT fecal immunochemical test, mt-sDNA multitarget stool DNA, CT computed tomography Note: due to differences in study methodologies, cells cannot be directly compared. Randomized controlled trials generally report results on an intent to screen basis whereas observational studies generally compare persons who underwent screening with persons who did not, raising concerns about self-selection bias. 
Table 2. Performance of Modalities Included in USPSTF Recommendations

\begin{tabular}{|c|c|c|c|c|c|c|c|}
\hline & & \multicolumn{5}{|c|}{ Sensitivity } & Specificity \\
\hline Screening Test & $\begin{array}{c}\text { Programmatic } \\
\text { Frequency }\end{array}$ & $\begin{array}{l}\text { Colorectal } \\
\text { Cancer }\end{array}$ & $\begin{array}{l}\text { Advanced } \\
\text { Adenoma }\end{array}$ & $\begin{array}{c}\text { Advanced } \\
\text { Serrated } \\
\text { Polyp }\end{array}$ & $\begin{array}{c}\text { Non- } \\
\text { advanced } \\
\text { Adenoma }\end{array}$ & $\begin{array}{c}\text { Non- } \\
\text { advanced } \\
\text { Serrated } \\
\text { Polyp }\end{array}$ & $\begin{array}{l}\text { (1 minus } \\
\text { positivity } \\
\text { rate in } \\
\text { normal } \\
\text { colon) }\end{array}$ \\
\hline \multicolumn{8}{|l|}{ stool-based tests } \\
\hline $\mathrm{gFOBT}^{14,15}$ & annually & $62 \%-79 \%$ & & $\bar{C}$ & & & $87 \%-96 \%$ \\
\hline FIT $^{20}$ & annually & $79 \%$ & $23.8 \%$ & $5 \%$ & $7.6 \%$ & & $94 \%$ \\
\hline FIT-DNA (mt-sDNA test) ${ }^{23}$ & every 3 years & $\begin{array}{c}\text { any, } \\
92.3 \% \text {; } \\
\text { stages } \\
1-3, \\
93.3 \%\end{array}$ & $\begin{array}{c}42.4 \% \\
\text { (includes } \\
\text { large } \\
\text { sessile } \\
\text { serrated } \\
\text { polyp) }\end{array}$ & $42.4 \%$ & $17.2 \%$ & & 86.6 \\
\hline \multicolumn{8}{|l|}{ direct visualization tests } \\
\hline flexible sigmoidoscopy & $\begin{array}{c}\text { every } 5 \mathrm{y} \\
\text { (or } 10 \mathrm{y} \text { if } \\
\text { combined with } \\
\text { annual FIT) }\end{array}$ & & within its & each, may b & imilar to $\mathrm{cc}$ & noscopy & \\
\hline colonoscopy $^{12,117-124}$ & every 10 years & & $\begin{array}{c}89.1 \%- \\
94.7 \% \\
\text { (size cutoff } \\
10 \mathrm{~mm})\end{array}$ & $\begin{array}{l}\text { range of } \\
\text { detection } \\
\text { rates: } \\
0.5-1.5 \%\end{array}$ & $\begin{array}{l}74.6 \%- \\
92.8 \% \\
\text { (size } \\
\text { cutoff } \\
6 \mathrm{~mm})\end{array}$ & $\begin{array}{c}\text { range of } \\
\text { detection } \\
\text { rates: } \\
6 \%-20 \%\end{array}$ & \\
\hline $\mathrm{CTC}^{12,125}$ & every 5 years & & $\begin{array}{c}89 \% \\
(82 \%- \\
96 \%) \\
\text { (size cutoff } \\
10 \mathrm{~mm})\end{array}$ & & $\begin{array}{c}86 \% \\
(78 \%- \\
95 \%) \\
\text { (size } \\
\text { cutoff } \\
6 \mathrm{~mm})\end{array}$ & $3 \%$ & $\begin{array}{c}\text { for } \geq 10 \\
\text { mm } \\
\text { adenoma: } \\
94 \% \\
(89 \%- \\
100 \%) ;\end{array}$ \\
\hline
\end{tabular}




\begin{tabular}{|c|c|c|c|c|}
\hline & & & & $\begin{array}{c}\text { for } \geq 6 \mathrm{~mm} \\
\text { adenoma: } \\
88 \% \\
(82 \%- \\
94 \%) \\
\end{array}$ \\
\hline \multicolumn{5}{|l|}{ serology tests } \\
\hline methylated septin 9 gene $* * 46$ & not defined & $\begin{array}{c}\text { any } \\
48.2 \% \text {; } \\
\text { stages } \\
1-3 \\
45.1 \%\end{array}$ & $11.2 \%$ & $91.5 \%$ \\
\hline
\end{tabular}

Note: Considerations beyond test performance that can aid clinicians make decisions, including test attributes, patient requirements, and interpretation of test results, have been detailed recently. ${ }^{126}$

** In the USPSTF recommendation statement, the table on characteristics of colorectal cancer screening strategies includes the footnote "Although a serology test to detect methylated SEPT9 DNA was included in the systematic evidence review, this screening method currently has limited evidence evaluating its use (a single published test characteristic study met inclusion criteria, which found it had a sensitivity to detect colorectal cancer of $<50 \%$ ). It is therefore not included in this table." 
Table 3. Projected Long-term Comparative Effectiveness of CRC Screening Strategies With Optimal Participation

\begin{tabular}{|l|c|c|c|c|c|c|c|c|}
\hline & \multicolumn{3}{|c|}{$\begin{array}{c}\text { Colorectal Cancer Incidence, } \\
\% \text { Reduction vs No Screening }\end{array}$} & \multicolumn{3}{c|}{$\begin{array}{c}\text { Colorectal Cancer Mortality, } \\
\text { \% Reduction vs No Screening }\end{array}$} \\
\hline & $\begin{array}{c}\text { SimCRC } \\
61,65\end{array}$ & $\begin{array}{c}\text { MISCAN } \\
61,65\end{array}$ & $\begin{array}{c}\text { CRC- } \\
\text { SPIN }\end{array}$ & $\begin{array}{c}\text { Ladabaum } \\
\text { et al. } 6,67\end{array}$ & $\begin{array}{c}\text { SimCRC } \\
61,65\end{array}$ & $\begin{array}{c}\text { MISCAN } \\
61,65\end{array}$ & $\begin{array}{c}\text { CRC- } \\
\text { SPIN } 61,65\end{array}$ & $\begin{array}{c}\text { Ladabaum et } \\
\text { al. }^{66,67}\end{array}$ \\
\hline $\begin{array}{l}\text { Colonoscopy every 10 years, } \\
\text { ages 50-75 years }\end{array}$ & $81 \%$ & $62 \%$ & $88 \%$ & $70 \%$ & $87 \%$ & $79 \%$ & $90 \%$ & $77 \%$ \\
\hline FIT yearly, ages 50-75 years & $67 \%$ & $47 \%$ & $72 \%$ & $57 \%$ & $81 \%$ & $72 \%$ & $81 \%$ & $72 \%$ \\
\hline $\begin{array}{l}\text { mt-sDNA every 3 years, } \\
\text { ages 50-75 years }\end{array}$ & $63 \%$ & $43 \%$ & $68 \%$ & $52 \%$ & $78 \%$ & $68 \%$ & $76 \%$ & $67 \%$ \\
\hline $\begin{array}{l}\text { CT colonography every 5 } \\
\text { years, ages 50-75 years }\end{array}$ & $77 \%$ & $51 \%$ & $78 \%$ & $67 \%$ & $85 \%$ & $72 \%$ & $82 \%$ & $77 \%$ \\
\hline $\begin{array}{l}\text { Sigmoidoscopy every 5 } \\
\text { years, ages 50-75 years }\end{array}$ & $68 \%$ & $56 \%$ & $59 \%$ & $44 \%$ & $74 \%$ & $72 \%$ & $62 \%$ & $49 \%$ \\
\hline
\end{tabular}

SimCRC, Simulation Model of Colorectal Cancer; MISCAN, Microsimulation Screening Analysis for Colorectal Cancer; CRC-SPIN,

Colorectal Cancer Simulated Population model for Incidence and Natural history.

SimCRC, MISCAN and CRC-SPIN are part of the National Cancer Institute's Cancer Intervention and Surveillance Modeling

Network (CISNET) consortium.

CT computed tomography, FIT fecal immunochemical test, mt-sDNA multitarget stool DNA 
Table 4. Cost Effectiveness of CRC Screening strategies vs No Screening

\begin{tabular}{|c|c|c|c|c|c|c|c|c|}
\hline & $\begin{array}{l}\text { Annual } \\
\text { gFOBT }\end{array}$ & $\begin{array}{l}\text { Biennial } \\
\text { gFOBT }\end{array}$ & Annual FIT & Biennial FIT & $\begin{array}{c}\text { FS every } 5 \\
\text { years }\end{array}$ & $\begin{array}{c}\text { Colonoscopy } \\
\text { every } 10 \\
\text { years }\end{array}$ & $\begin{array}{c}\text { CT } \\
\text { colonography } \\
\text { every } 5 \text { years }\end{array}$ & $\begin{array}{c}\text { mt-sDNA } \\
\text { test every } 3 \\
\text { years }\end{array}$ \\
\hline \multicolumn{9}{|c|}{ Systematic Review 2010-2017, 33 studies (17 Europe, 11 North America, 4 Asia, 1 Australia), $2016 \$^{67,70}$} \\
\hline LY gained & $0.01-0.12$ & $0.01-0.05$ & $0.01-0.15$ & $0.01-0.10$ & $0.02-0.14$ & $0.02-0.18$ & -- & -- \\
\hline $\begin{array}{l}\text { QALY } \\
\text { gained }\end{array}$ & $0.07-0.49$ & $0.01-0.32$ & $0.01-0.80$ & $0.01-0.70$ & $0.01-0.07$ & $0.02-0.22$ & -- & -- \\
\hline $\begin{array}{l}\text { Cost/LY } \\
\text { gained }\end{array}$ & $\begin{array}{c}\mathrm{CS}-\$ 4000 \\
{[\$ 50,000]}\end{array}$ & $\begin{array}{c}\mathrm{CS}-\$ 3000 \\
{[\$ 45,000]}\end{array}$ & $\begin{array}{c}\mathrm{CS}-\$ 9000 \\
{[\$ 24,000]}\end{array}$ & $\begin{array}{c}\mathrm{CS}-\$ 4000 \\
{[\$ 24,000]}\end{array}$ & $\begin{array}{c}\mathrm{CS}-\$ 7000 \\
{[\$ 67,000]}\end{array}$ & $\begin{array}{c}C S- \\
\$ 27,000 \\
{[\$ 52,000]}\end{array}$ & $\mathrm{CS}-\$ 16,000$ & $\begin{array}{l}\$ 9,000- \\
\$ 11,000\end{array}$ \\
\hline $\begin{array}{l}\text { Cost/QALY } \\
\text { gained }\end{array}$ & $\begin{array}{c}\text { CS - } \\
\$ 15,000\end{array}$ & CS - $\$ 6,000$ & $\begin{array}{c}C S-\$ 5,000 ; \\
\quad[\$ 33,000]\end{array}$ & CS - \$7000 & $\begin{array}{c}\mathrm{CS}-\$ 8000 \\
{[\$ 45,000]}\end{array}$ & $\begin{array}{c}C S- \\
\$ 15,000 \\
{[\$ 40,000]}\end{array}$ & $\begin{array}{c}\$ 3000- \\
\$ 11,000 \\
{[\$ 59,000]}\end{array}$ & $\begin{array}{c}\$ 15,000- \\
\$ 30,000\end{array}$ \\
\hline \multicolumn{9}{|c|}{ Review 1993-2009, 32 unique models (10 Europe, 14 North America, 5 Asia, 3 Australia), $2010 \$ \$^{69}$} \\
\hline $\begin{array}{l}\text { LY or } \\
\text { QALY } \\
\text { gained }\end{array}$ & $0.01-0.16$ & $0.01-0.03$ & & & $0.01-0.11$ & $0.02-0.18$ & -- & -- \\
\hline $\begin{array}{l}\text { Cost/LY or } \\
\text { Cost/QALY } \\
\text { gained }\end{array}$ & $\begin{array}{c}C S- \\
\$ 26,000 \\
{[\$ 53,000]}\end{array}$ & $\begin{array}{l}\$ 3000- \\
\$ 16,000\end{array}$ & $\mathrm{CS}$ & 26,000 & $\begin{array}{c}\text { CS - } \\
\$ 30,000 ; \\
{[\$ 57,000]}\end{array}$ & $\mathrm{CS}-\$ 32,000$ & $\mathrm{CS}-\$ 36,000$ & $\begin{array}{c}\$ 600- \\
\$ 32,000\end{array}$ \\
\hline \multicolumn{9}{|c|}{ Systematic Review for USPSTF 1993-2001, 7 studies (7 US), $2000 \$ \$^{68}$} \\
\hline $\begin{array}{l}\text { Cost/LY } \\
\text { gained }\end{array}$ & $\begin{array}{l}\$ 6000- \\
\$ 18,000\end{array}$ & -- & & & $\begin{array}{l}\$ 12,000- \\
\$ 39,000\end{array}$ & $\begin{array}{l}\$ 9,000- \\
\$ 22,000\end{array}$ & -- & -- \\
\hline
\end{tabular}

CS, cost saving; FS, flexible sigmoidoscopy; LY, life-year; USPSTF, US Preventive Services Task Force; QALY, quality-adjusted life-year.

Notes: Ranges reported in published studies are shown; single values judged to be outliers at the high end of the range are shown separately in brackets. Costs are rounded to nearest \$1000, and LYs and QALYs are rounded to nearest 0.01, and all reflect annual discounting, usually at rates $3 \%-5 \%$.

All potentially relevant published studies were included in the systematic reviews. Some studies reported life-years, and some qualityadjusted life-years, so both outcomes are shown. 
All currencies were converted to US dollars and updated to a given year, which differed in each review.

Columns are not directly comparable to each other because not all studies in a review contributed to every cell or explicitly compared

all strategies to each other. 

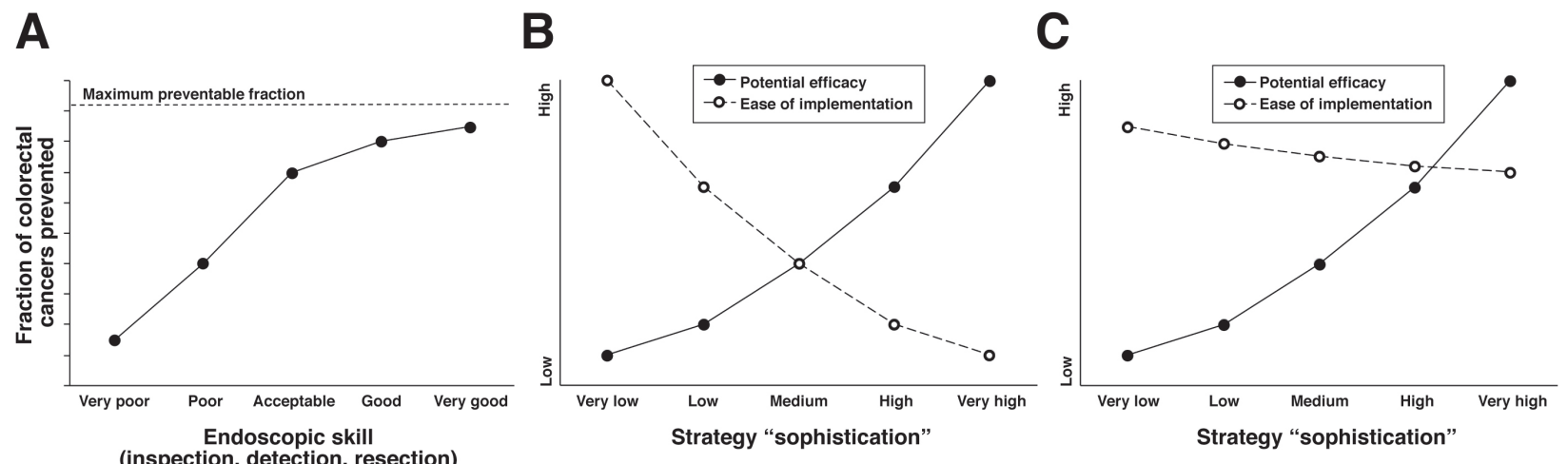
(inspection, detection, resection) 